\title{
Group interprofessional chronic pain management in the primary care setting: A pilot study of feasibility and effectiveness in a family health team in Ontario
}

\author{
Ricardo N Angeles MD MPH MHPEd ${ }^{1}$, Dale Guenter MD MPH CCFP' ${ }^{1}$, Lisa McCarthy PharmD MSc ${ }^{1,2}$, \\ Martha Bauer MSc OT ${ }^{1}$, Miriam Wolfson MSW ${ }^{1}$, Maria Chacon MD ${ }^{1}$, Lana Bullock MD CCFP1
}

RN Angeles, D Guenter, L McCarthy, et al. Group interprofessional chronic pain management in the primary care setting: A pilot study of feasibility and effectiveness in a family health team in Ontario. Pain Res Manag 2013;18(5):237-242.

BACKGROUND: Approximately $18.9 \%$ of Canadians live with chronic pain. Primary care reform in Ontario presents unique opportunities to assess approaches to help these patients.

OBJECTIVE: To assess the feasibility of an interprofessional primary carebased program for patients living with chronic pain, and to examine the potential impact of such a program on quality of life and health resource utilization.

METHODS: An embedded mixed-methods evaluation (randomized controlled trial with waiting list control and semistructured interviews) of an eight-week series of small group sessions exploring multifactoral aspects of pain management was performed. Participants were randomly assigned to early intervention (EI) or delayed intervention (DI) groups. All participants received the intervention; the DI group served as a control group for comparison with the EI group. Outcomes included the Short Form-36 Health Survey version 2 (SF-36v2), medication use and health care utilization. Qualitative interviews were conducted to identify areas for program improvement.

RESULTS: A total of 240 patients were recruited and 63 agreed to participate. The mean $( \pm S D)$ age of the participants was $55 \pm 14.1$ years and $62.3 \%$ were female. There was no significant difference in the mean change in SF-36v2 summary scores between the EI and DI groups. However, the SF-36v2 subscale score for bodily pain was significantly improved in the EI group compared with the DI group after six months of observation (mean difference $=$ 13.1 points; $\mathrm{P}<0.05$ ). There was also significant improvement in this score when both groups were pooled and aggregate preintervention and postintervention scores were compared. There was a significant decrease in the mean number of clinic visits in the six-month period following the intervention compared with the six-month period before the intervention $(\mathrm{P}=0.043)$.

CONCLUSION: An interprofessional program in primary care for patients living with chronic pain may lead to improvements in quality of life and health resource utilization. The challenges to the feasibility of the program and its evaluation are recruitment and retention of patients, leading to the conclusion that the program, as it was conducted in the present study, is not appropriate for this setting.

Key Words: Chronic pain education; Family medicine; Interprofessional; Primary care

A ccording to a recent survey, the prevalence of chronic noncancer pain in Canada, defined as pain from various conditions lasting six months or longer, is estimated to be $18.9 \%(1-3)$. This translates to a total direct cost to the health care system of $\$ 6.02$ billion per year, $\$ 4.25$ billion in excess of the costs expected for those without chronic pain (4). These costs are expected to increase to an estimated $\$ 10.29$ billion per year (an excess of $\$ 7.26$ billion) by 2025 and, notably, do not include societal costs related to disability or lost productivity.
La gestion interprofessionnelle de la douleur chronique d'un groupe en première ligne : un projet pilote de faisabilité et d'efficacité au sein d'une équipe de santé familiale de l'Ontario

HISTORIQUE : Environ 18,9 \% des Canadiens vivent avec des douleurs chroniques. La réforme des soins de première ligne de l'Ontario offre une occasion idéale d'évaluer les démarches en vue d'aider ces patients. OBJECTIF : Évaluer la faisabilité d'instaurer un programme interprofessionnel de soins de première ligne à l'intention des patients qui vivent avec des douleurs chroniques et en examiner les répercussions potentielles sur la qualité de vie et l'utilisation des ressources de santé.

MÉTHODOLOGIE : Les chercheurs ont procédé à une évaluation intégrée à méthodologie mixte (essai aléatoire et contrôlé associé à des sujets témoins sur la liste d'attente et à des entrevues semi-structurées) d'une série de séances en petits groupes répartie sur huit semaines portant sur les aspects multifactoriels de la gestion de la douleur. Ils ont réparti aléatoirement les participants entre un groupe d'intervention rapide (IR) et un groupe d'intervention tardive (IT). Tous les participants ont pris part à l'intervention. Le groupe d'IT servait de groupe témoin comparé au groupe d'IR. Les issues incluaient la version 2 du sondage court en 36 questions (SC-36v2), l'utilisation de médicaments et le recours au système de santé. Des entrevues qualitatives ont permis de déterminer les améliorations à apporter au programme.

RÉSULTATS : Au total, 240 patients ont été recrutés et 63 ont accepté de participer. Les participants avaient un âge moyen ( \pm ÉT) de 55 $\pm 14,1$ ans, dont $62,3 \%$ de femmes. Les chercheurs n'ont constaté aucune différente significative du changement moyen des indices sommaires du SC-36v2 entre le groupe d'IR et le groupe d'IT. Cependant, au cours des six mois d'observation, l'indice de la sous-échelle du SC-36v2 relatif à la douleur corporelle s'améliorait considérablement dans le groupe d'IR par rapport au groupe d'IT (différence moyenne $=13,1$ points; $\mathrm{P}<0,05$ ). Les chercheurs ont également constaté une amélioration importante de cet indice lorsque les deux groupes étaient conjugués et que les indices globaux étaient comparés avant et après l'intervention. Ils ont remarqué une diminution importante du nombre moyen de visites à la clinique dans les six mois suivant l'intervention par rapport aux six mois précédant l'intervention ( $\mathrm{P}=0,043)$. CONCLUSION : Un programme interprofessionnel en soins de première ligne destiné aux patients qui vivent avec des douleurs chroniques pourrait améliorer la qualité de vie et réduire le recours aux ressources de santé. Les problèmes de recrutement et de rétention des patients nuisent à la faisabilité du programme et à son évaluation, ce qui mène à la conclusion que le programme, dans la forme où il a été mené dans la présente étude, ne convient pas à ce milieu.

Programs delivered by an interprofessional team for patients living with pain have been demonstrated to produce many benefits including improved function and coping behaviours, sooner return to work, closure of disability claims and reduced costs to the health care system (5-7). The most effective programs include cognitive, behavioural and physical activation modalities that are focused on function and coping rather than pain reduction (5-7). Additionally, programs are optimized when implemented in the context of continuity of care $(8,9)$. Primary

${ }^{1}$ Department of Family Medicine, Faculty of Health Sciences, McMaster University, Hamilton; ${ }^{2}$ Leslie Dan Faculty of Pharmacy, University of

Toronto, Toronto, Ontario

Correspondence: Dr Ricardo Angeles, Department of Family Medicine, McMaster University, McMaster Innovation Park, Suite 201A,

175 Longwood Road S, Hamilton, Ontario L8P OA1. Telephone 905-525-9140 ext 28509, fax 905-527-4440, e-mail angelesric@gmail.com 


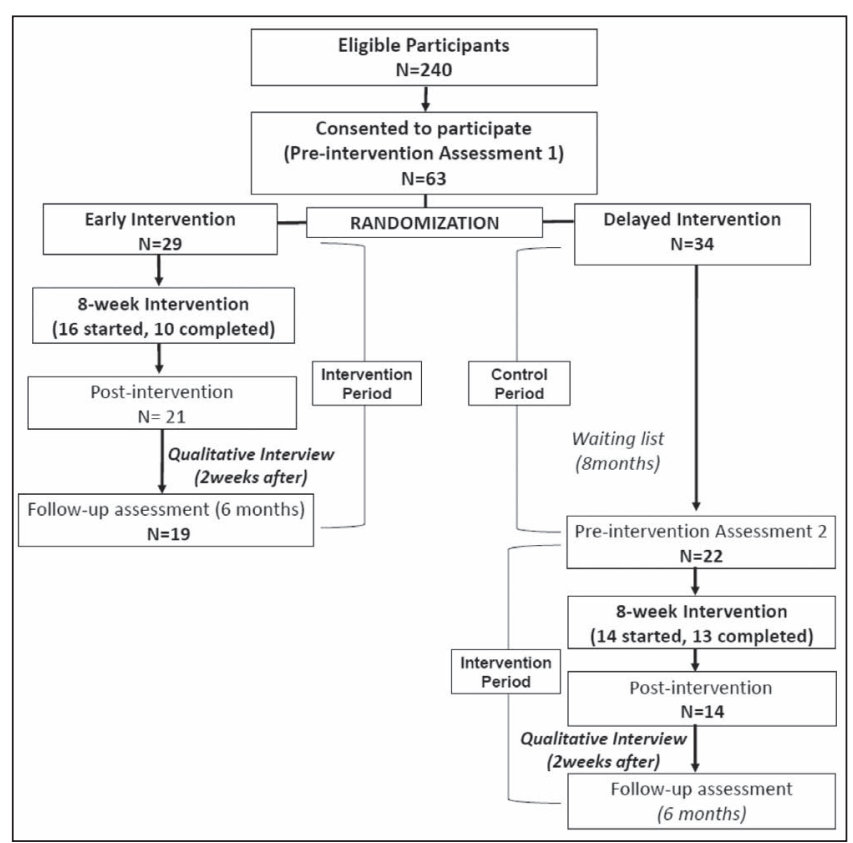

Figure 1) Study design

care clinicians are at the frontline of the management of chronic noncancer pain (3). On average, family practitioners in Canada treat 45 chronic pain patients per month, $83.3 \%$ of whom experience noncancer-related pain (10). Although a variety of pain management approaches are offered through interprofessional programs in Ontario, capacity and access are inadequate given the burden of disease. Translating interprofessional interventions that have been proven effective into the primary care setting has been resource intensive in the past $(8,9,11)$.

At the McMaster Family Health Team (MFHT) in Hamilton, Ontario, we sought to design and evaluate the feasibility of an interprofessional chronic pain management program using resources available within the practice. The present study also evaluated the potential impact of the program and highlights the process issues regarding the implementation of the program in the family health team setting.

\section{Research design}

\section{METHODS}

The present embedded experimental mixed-methods study (12) used a randomized controlled trial (RCT) with a waiting-list control group $(7,13)$ to assess the impact of a series of small group sessions on quality of life (QOL) and health care utilization in patients with chronic noncancer pain. Qualitative interviews with program participants were included for additional outcome and process evaluations (Figure 1).

Participants were randomly assigned to one of two groups: the 'early intervention' (EI) group or the waiting list ('delayed intervention' [DI]) group. The EI initially served as the experimental group while the DI served as the control group. After serving as the control group for the eight-month initial phase, the DI also received the intervention. At the outset, all participants were informed of the process and interventions they would receive but not informed about the group to which they were assigned. Individuals in the DI group were informed that they were wait-listed and that the intervention would be delivered based on a schedule. All participants were followed-up for six months after the end of the intervention.

Semistructured qualitative interviews were conducted two weeks after the group sessions ended to determine the perceptions of participants regarding the program's impact on their daily lives as well as their experiences during the actual intervention sessions. The interviews were also used to identify aspects of the program that were perceived as beneficial and components requiring modification.
The present study was reviewed and approved by the Hamilton Health Sciences/Faculty of Health Sciences, McMaster University Research Ethics Board (Hamilton, Ontario).

\section{Research setting}

The intervention was developed for the two clinic sites of the MFHT, McMaster Family Practice and Stonechurch Family Health Centre (Hamilton, Ontario). These clinics constitute the majority of the teaching practices of the Department of Family Medicine of McMaster University. Together they included approximately 25,000 active patients served by 25 family physicians, 40 family medicine residents, nurse practitioners, social workers, dieticians and pharmacists at the time of the study. The MFHT is typical of the model that has been in evolution in Ontario since 2006. In this model, a diverse group of allied health clinicians is funded to work with family physicians to provide a comprehensive package of primary care services.

\section{Participants}

Participants were eligible if they were patients of the MFHT, were 18 years of age or older, and were experiencing chronic pain (musculoskeletal or neuropathic pain lasting at least six months). Participants were excluded if they met any of the following criteria: chronic pain related to cancer, pelvic pain or headache (because the diagnosis and management of these conditions is distinct in many ways from musculoskeletal pain); inability to speak or write in English (because group sessions and questionnaires were conducted in English); inability to attend and participate in group treatment sessions on their own; substance use or mental health problems of a severity that would make group participation too challenging; if they were participating in another cognitive-behavioural pain management program at the time of the research; or if they were receiving palliative care or had been diagnosed with an illness expected to cause death within one year.

\section{Recruitment}

Clinicians in the MFHT clinics were asked to identify potential participants from their practices based on the inclusion criteria by assigning a label within the electronic health record (EHR). EHRs were also searched to identify potential candidates from all patients who received a prescription for a long-acting opioid medication within the previous year.

Potential participants were sent letters of invitation from their family physician to participate in group treatment and in research. Research staff subsequently made three attempts to contact patients to provide additional information regarding the project. Interested patients were then invited to an information session after which they could opt to provide consent. Enrollment occurred between December 2009 and March 2010.

\section{Sample size}

As a pilot study, the primary research question was whether a program such as that described could be implemented, and whether such a research design could be conducted successfully. Thus, although an RCT was conducted, detecting statistically significant differences was considered to be irrelevant to the main research question. The sample size was initially computed based on the expected change in the Short Form-36 Health Survey version 2 (SF-36v2) QOL scores (mean difference of $5 \pm 8$ points), based on previous literature $(9,11,14)$. The target sample size was 40 for an alpha of 0.05 and a power of 0.8 (15). However, there were only 29 participants in the EI group and 34 in the DI group who consented to participate. This decreased the power to 0.7 .

\section{Randomization}

Patients who consented and completed the baseline study questionnaires were randomly assigned to either EI or DI groups using the online Research Randomizer (16).

\section{Intervention}

The literature describes programs with a wide variety of duration, frequency and content of sessions. In one recent review of 15 programs 
(17), patients were generally selected with minimal exclusion criteria, sessions varied from daily to monthly for three weeks to nine months, and all used a combination of medical, psychological and behavioural, education and physical reconditioning treatments. Because the MFHT has access to occupational therapists, social workers, pharmacists and physicians who all have an interest in chronic pain management, a modified multidisciplinary program customized to this setting was designed. Curriculum and content that was consistent with the literature and of a duration and intensity that was practical for participants' daily lives and manageable for human resources in the MFHT was chosen.

The program consisted of $2 \mathrm{~h}$ group sessions once per week for eight weeks. The group setting was used to develop peer support, to identify a variety of personal experiences and perspectives, and to improve insight and motivation. The curriculum was developed and cofacilitated by an occupational therapist ( $\mathrm{MB}$, coinvestigator) and a social worker (MW, coinvestigator), both with experience in pain management and small group facilitation. Topics for the curriculum were developed through a literature review of previously successful group therapy models for patients with pain $(5-9,11)$ and a discussion of concerns with MFHT clinicians regarding what would be helpful for their patients. During specific sessions, physicians, pharmacists, dieticians and physiotherapists were involved in the groups as resource persons.

Group sessions included the following: education regarding the nature of chronic pain, pacing and goal setting, and medication management; practice in mindfulness relaxation techniques; cognitive reflection on beliefs, impulses and obsessional thoughts about pain; and practice of physical activation techniques (modified fitness and practice of modified postures or positions for various activities of daily living, including self-care and housekeeping tasks). The facilitators followed an implementation manual regarding how to conduct the sessions.

\section{Outcome measures and research instruments}

The present study assessed process and outcome measures. Process measures included data regarding patient attendance and program compliance. Postintervention qualitative interviews with study participants were conducted with seven main stem open-ended questions, with several probing questions to assess their perceptions and views regarding the conduct of the program.

The two primary outcomes assessing the impact of the program were QOL and health care utilization. QOL was measured using the SF-36v2 because this tool had previously been used in a broad range of studies investigating chronic musculoskeletal pain $(9,11,14)$.

Health care utilization was measured based on patients' number of clinic visits due to chronic pain, number of requests for early medication refills or for dosage increases for a regularly prescribed opioid and number of visits to allied health care professionals for chronic pain concerns. These were measured through a chart audit process and not by selfreport.

Participants were screened for alcohol and substance abuse using the CAGE Adapted to Include Drugs (CAGE-AID) questionnaire $(18,19)$. The CAGE-AID is a four-item questionnaire in which an affirmative response for each item earns one point. One point indicates possible problems with alcohol and substance abuse, while two or more points represents probable problems (20). A pain medication use questionnaire was adapted by the research team for use in patients taking pain medications (21).

\section{Data collection}

Data from the EI group were collected on three occasions: at baseline (preintervention), immediately postintervention (postintervention) and six months postintervention (follow-up). The DI group was assessed on four occasions: at baseline (preintervention 1), immediately before (preintervention 2) and after the intervention (postintervention), and six months postintervention (follow-up). All questionnaires were self-administered. Pre- and postintervention questionnaires were completed on-site while the follow-up assessments used mailed questionnaires.

A retrospective review of participants' EHRs was used to examine health care utilization in the period six months before and after the group sessions. Qualitative interviews were administered two weeks after the intervention in each group. Consecutive sampling was used based on participant availability for phone interviews. Data collection continued until saturation.

\section{Data analysis}

The mean change in SF-36v2 QOL scores was compared between participants of the EI (preintervention to follow-up six months postintervention) and DI (preintervention 1 to preintervention 2 -six months). The number of clinic visits and items in the pain medication use questionnaires were also compared between the two groups.

Patients in the two groups were combined for aggregate EI and DI data to assess the longitudinal change in SF-36v2 scores from immediately before, immediately after and six months after the intervention. This was performed to assess for immediate and medium-term effects of the invention.

Between-group scale outcomes were analyzed using independentsamples $t$ tests. $\chi^{2}$ tests were used for nominal outcomes. Multilevel regression was used to assess changes in the SF-36v2 over time $(22,23)$. All analyses followed the intention-to-treat principle. All data were analyzed using SPSS version 20.0 (IBM Corporation, USA).

Process outcomes relating to attendance and compliance were summarized using descriptive statistics. For the qualitative process evaluation, common themes were elicited during interviews based on the verbatim statements of the respondents.

\section{RESULTS}

\section{Attendance and program compliance}

A total of 240 patients from the MFHT clinics were eligible to participate based on the inclusion criteria. Seventy-five patients provided verbal consent to attend the orientation sessions, 64 actually attended the orientation session, and 63 consented to participate in the study and completed baseline assessment questionnaires. Among these patients, 30 initially attended the program and 23 completed the program (attended at least six of the eight sessions). Figure 1 summarizes the number of participants who attended the intervention in reference to the study design.

\section{Participant profile}

Table 1 summarizes participants' characteristics on entering the study. Although the 63 participants were all randomly assigned (31 assigned to EI, 32 assigned to DI), two subjects assigned to the EI group requested to attend the DI group with their partners/spouses; this was permitted to maximize willingness to participate.

The majority of patients in both the EI and DI groups were female, in the age group of 40 to 59 years and had completed college education or higher. More than $40 \%$ of the participants reported that they had lived with chronic pain for 15 years or more. In both groups, most were unemployed at the time of enrollment; however, twice as many of the DI participants had been working before developing their chronic pain than in the EI group (72.7\% versus 34.5\%). The reasons for this are unexplained. Most of the participants stated that their chronic pain was due to a disease process, while nearly one-third stated that it was due to a work-related accident. Based on the CAGE-AID questionnaire, less than $20 \%$ of participants from both groups demonstrated possible or probable problems with alcohol or drugs.

Multivariate logistic regression was used to explore factors predictive of those who were likely to attend and complete the program. Potential factors tested included age, education, sex, duration of pain, marital status and whether they were receiving disability pensions. Only age was noted to be a significant predictive factor for completing the sessions. Younger participants were more likely to attend than older participants. 
TABLE 1

\section{Participant profile}

\begin{tabular}{|c|c|c|c|}
\hline \multirow[b]{2}{*}{ Demographic variable } & \multicolumn{2}{|c|}{ Intervention group } & \multirow[b]{2}{*}{$\begin{array}{c}\text { Total } \\
(n=60)\end{array}$} \\
\hline & $\begin{array}{l}\text { Early } \\
(n=29)\end{array}$ & $\begin{array}{c}\text { Delayed } \\
(n=34)\end{array}$ & \\
\hline $40-59$ years of age & 44.8 & 56.2 & 50.8 \\
\hline Female sex & 58.6 & 66.7 & 62.9 \\
\hline Completed college education or higher & 60.7 & 64.6 & 62.7 \\
\hline Pain duration $\geq 15$ years & 46.2 & 48.4 & 47.4 \\
\hline \multicolumn{4}{|l|}{ Working full-time } \\
\hline Before onset of pain & 34.5 & 72.7 & 54.8 \\
\hline After onset of pain & 10.3 & 18.2 & 14.5 \\
\hline \multicolumn{4}{|l|}{ Receiving government compensation } \\
\hline Before onset of pain & 10.3 & 6.1 & 8.1 \\
\hline After onset of pain & 31.0 & 18.2 & 24.2 \\
\hline \multicolumn{4}{|l|}{ Cause of pain (multiple response) } \\
\hline Work-related accident & 27.6 & 33.3 & 30.6 \\
\hline Non work-related accident & 24.1 & 30.3 & 27.4 \\
\hline Disease process & 65.5 & 54.5 & 59.7 \\
\hline \multicolumn{4}{|l|}{ CAGE-AID screening tool } \\
\hline Possible problem with alcohol or drugs & 10.3 & 15.2 & 12.9 \\
\hline Probable problem with alcohol or drugs & 6.8 & 6.1 & 6.4 \\
\hline
\end{tabular}

Data presented as \%. CAGE-AID CAGE Questionaire Adapted to Include Drugs

TABLE 2

Comparison of mean change in SF-36v2 scores between early intervention group (after intervention) and delayed intervention group (during waiting period)

\begin{tabular}{|c|c|c|c|}
\hline \multirow[b]{2}{*}{ SF-36v2 component } & \multicolumn{2}{|c|}{ Mean change in score } & \multirow[b]{2}{*}{$\mathbf{P}$} \\
\hline & $\begin{array}{c}\text { Early } \\
\text { intervention } \\
\text { (postintervention) } \\
(n=19)\end{array}$ & $\begin{array}{c}\text { Delayed } \\
\text { intervention } \\
\text { (waitlist period) } \\
(n=22)\end{array}$ & \\
\hline Role physical & $\downarrow 15.3$ & $\uparrow 3.4$ & 0.01 \\
\hline Physical functioning & $\downarrow 4.2$ & $\downarrow 7.3$ & 0.66 \\
\hline Bodily pain & $\uparrow 9.2$ & $\downarrow 3.9$ & $<0.01$ \\
\hline General health & $\downarrow 1.8$ & $\uparrow 0.3$ & 0.76 \\
\hline Physical component summary & $\downarrow 2.9$ & $\downarrow 3.0$ & 0.98 \\
\hline Role emotional & $\uparrow 2.6$ & $\uparrow 3.7$ & 0.92 \\
\hline Vitality & $\uparrow 4.0$ & $\uparrow 3.4$ & 0.93 \\
\hline Mental health & $\uparrow 3.0$ & $\uparrow 3.5$ & 0.94 \\
\hline Social functioning & $\uparrow 3.2$ & $\uparrow 2.7$ & 0.95 \\
\hline Mental component summary & $\uparrow 3.6$ & $\uparrow 3.6$ & 1.00 \\
\hline
\end{tabular}

$\downarrow$ Decrease; $\uparrow$ Increase; SF-36v2 Short Form-36 Health Survey version 2

\section{QOL}

The baseline SF-36v2 QOL score was not significantly different in the summary score and the subscales, except the 'social functioning' subscale, for which the EI group (mean = 47.5) exhibited significantly higher QOL scores than the DI group $($ mean $=30.3)$. Table 2 shows the mean change in QOL scores from the pre- to postintervention period for the EI group and during the waitlist period for the DI. The data show that there was a significant difference in the change scores for the role physical (RP) and bodily pain domains. There was a decrease (reduced QOL) in the RP change score by 15.3 points in the EI group, while there was an increase in the change score of the DI group by 3.4 points during the waiting time period. Conversely, there was an improvement in the QOL change score for bodily pain in the EI group by 9.2 points, while there was a decline in the DI group by 3.9 points.

Figure 2 illustrates the changes in QOL scores preintervention, immediately postintervention, and after the six-month follow-up period. Significant changes were observed in the RP and bodily pain

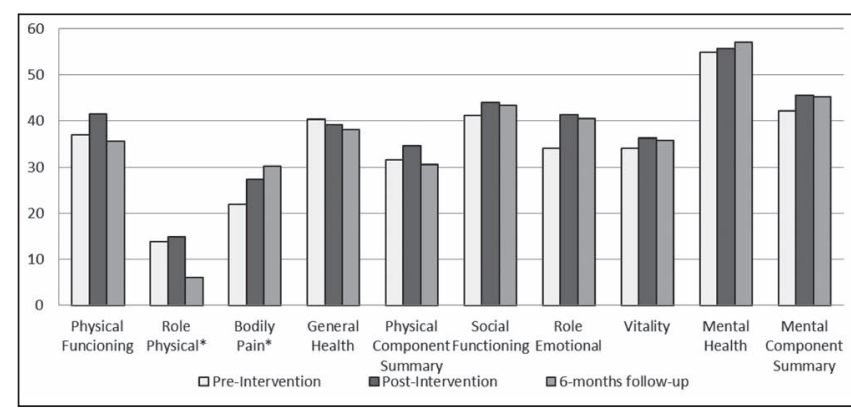

Figure 2) Change in Short Form-36 Health Survey version 2 quality of life score over time. *Statistically significant changes

domains. There was a significant decline in the QOL scores for the $\mathrm{RP}$ domain from postintervention to six-month follow-up. On the other hand, QOL scores for bodily pain significantly improved from pre- to postintervention and further improved during the six-month follow-up period. There were no changes in any of the other domains and summary scores. Furthermore, there was no significant change in the health transition question of the SF-36v2 (regarding perception of current state of health compared with one year previously) between preintervention (mean 2.5) and postintervention (mean 2.9).

\section{Health care utilization}

There was a significant difference in the mean number of clinic visits for participants (EI and DI combined) during the six months before (mean $[ \pm \mathrm{SD}] 3.7 \pm 3.2$ visits) and six months following (2.9 \pm 2.9 visits) the intervention $(\mathrm{t}[59]=2.06 ; \mathrm{P}=0.043)$. There was also a nonsignificant trend toward fewer clinic visits among the EI group during the six months following the intervention (2.34 \pm 2.39$)$ compared with the DI during the six months waiting period $(3.53 \pm 2.60 ; \mathrm{t}[56]=-1.78 ; \mathrm{P}=0.08)$.

Among the EI patients, $7.7 \%$ requested early refill of their opioid medications during the six months after the intervention compared with $25 \%$ of DI patients during the six-month waiting period $\left(\chi^{2}[1, n=58]=3.012 ; P=0.08\right)$. In addition, $11.5 \%$ of EI patients reported an increase in the dose of opioid medications compared with $9.4 \%$ of the DI group $\left(\chi^{2}[1, n=58]=0.072 ; P=0.56\right)$. Both parameters were not significantly different between the two groups. The use of allied health care personnel was also not significantly different between the two groups.

\section{Pain medication use}

At baseline, $91.4 \%$ of all participants reported that they were currently taking medications for pain. Approximately $50.0 \%$ reported previous use of natural health products for pain, while $36.8 \%$ had taken medications not prescribed by their doctor or nurse.

Based on the results of the pain medication use questionnaires, there was no significant difference in the perceptions and behaviours of EI patients postintervention compared with the DI patients during the waitlist period.

\section{Qualitative process evaluation}

The participants were initially asked about the challenges they faced in attending the group sessions as well as the factors that influenced them to attend the program. Many of the participants mentioned logistical issues that made it difficult to attend such as taking time off work, availability during the scheduled sessions and conflicting appointments. Others mentioned problems related to pain that made it difficult to attend or tolerate prolonged sitting. Some participants believed that the program was not well suited to them ("It was not for me"; "I don't need psychological help, my problem is physical"), and some believed an insufficient number of sessions was provided. Some participants spoke about recognizing that they "need some help", and that the curriculum provided some tools that would enable them to cope better.

Several suggestions were presented by the participants relating to the program, topics and delivery of the sessions. Some participants suggested having a refresher course, increasing the number of group 
sessions and scheduling sessions in the afternoon. Other participants suggested covering more topics such as alternative medicine, sleep and practice of meditation. Some suggested allotting more time for participants to speak and ensuring that all participants had equal opportunity to discuss their own situation.

\section{DISCUSSION}

The primary objective of pilot studies is to assess feasibility before designing a large RCT. Pilot studies contribute to the likelihood of success of future larger-scale studies by determining recruitment and retention rates, assessing time and budget problems, estimating variability of outcomes and allowing selection of the most appropriate primary outcome measure. Publishing pilot studies benefits the research community by "1) avoiding duplicate of efforts/resources in assessing feasibility; 2) efficiently updating other researchers regarding feasibility issues during electronic information search; and 3) providing accountability by ensuring best possible use of research results" (24). We conclude from our pilot study that it is not feasible to proceed with a larger trial adequately powered to detect a statistically significant difference in our primary outcome, unless we make significant changes to the method of recruitment and outcome measurement. We believe our findings are instructive for other investigators hoping to establish similar programs in the primary care setting. Our findings also suggest that there may be benefits from our intervention, but conclusive evidence would require a larger trial with a different design.

One major concern was the process of participant recruitment and retention in the program. Only a small number of eligible participants attended the program despite personalized letters from physicians and offering six orientation sessions at various times during the day. There was also a significant dropout rate among participants who attended the EI group, whose treatment sessions began within two weeks of their orientation session, possibly too soon for confident participation. Age was the only statistically significant factor predicting attendance to the group. We speculate that younger patients may be more optimistic regarding the potential for rehabilitation, or have fewer comorbidities restricting their participation. Based on the qualitative interview, participants reported logistical and pain issues as the major deterrents for attending the program, while others clearly believed that the content was not relevant to them. Previous studies have shown dropout rates of $40 \%$ to $60 \%$ for patients attending pain programs $(25,26)$ and have found that it is difficult to predict factors associated with dropping out $(26,27)$. Interestingly, older age and a difference in expectation of the program have been cited in the literature as reasons for dropping out of the program $(28,29)$. This is consistent with the findings of our study.

Our results suggest that pain improved over the course of the intervention, and, indeed, that this improvement was sustained. This finding is difficult to reconcile with the decrease in the amount of activity participants reported performing over the course of the intervention. The RP subscale assesses problems related to work and other activities related to a physical condition (30). This indicates that participants experienced more problems with work and other activities after the intervention, which contradicts our qualitative results indicating that participants felt better. Examining the survey items within this subscale, we noted a significant increase in respondents who reported cutting down on their activities. This may be related to curriculum content regarding pacing, in which respondents were taught to divide activities into smaller workloads to prevent exacerbations of their pain. The SF-36v2 considers this a decrease in QOL, while, in fact, it may reflect an important compromise between the amount a person tries to physically achieve and their ability to cope in other ways.

There was a significant decrease in the number of clinic visits after attending the group sessions. This could be interpreted as a possible improvement in self-efficacy and the group sessions may represent a valuable routine connection with health care providers that may counterbalance routine clinical care. This is supported by the qualitative findings that several strategies taught during the group session helped in managing pain and may have a long-term impact on their daily activities. The nonsignificant trend toward fewer clinic visits among the EI group at postintervention could be due to improved coping in this group or worsening condition of participants in the DI group during the waiting period.

We also observed a nonsignificant trend toward decreased requests for early prescription refills among participants who underwent the intervention. This observation is worthy of further study because this could have an important impact on the QOL of individuals with chronic pain, satisfaction of clinicians and cost of health service utilization. This trend may have been due to increased self-efficacy among participants who attended the intervention that translated to lowered dependence on pharmaceuticals and increased self-management coping skills.

Previous studies have shown that cognitive behavioural treatment by an interprofessional team is significantly better than typical care/waitlist control in improving patients' perception of pain (5-7). These studies have also shown improvements in the daily functioning of these patients. In our study, it is unclear whether this occurred, because the physical functioning subscale of the SF-36v2 showed no improvement and the RP subscale was in favour of the waitlist control group. The significant decrease in the number of clinic visits is consistent with other studies using more resource-intensive interventions $(9,14)$.

Although the present study was conducted in a specific primary care clinic setting, the results may be generalizable to other primary care settings, given the reforms that are occurring and the emphasis on interprofessional care throughout the health system. Using the expertise and resources available to the clinic (occupational therapist, physical therapist, social worker, pharmacists, physicians, nurses and dietitians) and appropriate training, this intervention can be conducted to improve care for patients with chronic pain.

Our observations over the course of the present pilot study lead us to believe that chronic pain management groups may be used in the primary care setting (especially if interprofessional teams are available), and that they may result in important improvements in pain and health resource utilization. Recruitment in this setting is difficult, and future work should explore strategies for appealing to patients to participate in groups and to screen for patients who will benefit most. We have also learned that selection of measurement tools must be appropriate for the specific intervention being evaluated. In our case, the SF-36v2 may not have been the most appropriate tool.

ACKNOWLEDGEMENTS: This project was supported by the Alternative Funding Program, Ontario Ministry of Health \& Long-Term Care. The sponsor had no role in study design, collection, analysis or interpretation of the data. Trial Registration: ClinicalTrials.gov NCT01517256

\section{REFERENCES}

1. Schoflocher D, Taenser P, Jovey R. The prevalence of chronic pain in Canada. Pain Res Manag 2011;16:445-50.

2. Moulin DE, Clark AJ, Speechley M, et al. Chronic pain in Canada: Prevalence, treatment, impact and the role of opioid analgesia. Pain Res Manag 2002;7:179-84.

3. Boulanger A, Clark AJ, Squire P, et al. Chronic pain in Canada: Have we improved our management of chronic noncancer pain? Pain Res Manag 2007;12:39-47.

4. Lynch ME, Schopflocher D, Taenzer P, Sinclair C. Research funding for pain in Canada. Pain Res Manag 2009;14:113-5.

5. Scascighini L, Toma V, Sprott H. Multidisciplinary treatment for chronic pain: A systematic review of interventions and outcomes. Rheumatology 2008;47:670-8.

6. McCracken LM, Turk D. Behavioral and cognitive-behavioral treatment for chronic pain: Outcome, predictors of outcome, and treatment process. Spine 2002;27:2564-73.

7. Morley S, Eccleston C, Williams A. Systematic review and metaanalysis of randomized controlled trials of cognitive behaviour therapy and behaviour therapy for chronic pain in adults, excluding headache. Pain 1999;80:1-13.

8. Dobscha SK, Corson K, Perrin NA, et al. Collaborative care for chronic pain in primary care: A cluster randomized trial. JAMA 2009;301:1242-52. 
9. Ables TA, Wasson JH, Seville JL, et al. A controlled trial of methods for managing pain in primary care patients with or without co-occurring psychosocial problems. Ann Fam Med 2006;4:341-50.

10. Morley-Forster PK, Clark AJ, Speechley M, et al. Attitudes toward opioid use for chronic pain: A Canadian physician survey. Pain Res Manag 2003;8:189-94.

11. Angst F, Verra ML, Lehmann S, et al. Clinical effectiveness of an interdisciplinary pain management programme compared with standard inpatient rehabilitation in chronic pain: A naturalistic, prospective controlled cohort study. J Rehabil Med 2009;41:569-75.

12. Cresswell JW, Plano Clark VL. Designing and Conducting Mixed Methods Research, 2nd edn. Los Angeles: Sage Publications 2011:53-106.

13. Ruwaard J, Broeksteeg J, Schrieken B, Emmelkamp P, Lange A. Web-based therapist-assisted cognitive behavioral treatment of panic symptoms: A randomized controlled trial with a three-year follow-up. J Anxiety Disord 2010;24:387-96.

14. Kroenke K, Bair MJ, Damush TM. Optimized antidepressant therapy and pain self-management in primary care patients with depression and musculoskeletal pain: A randomized controlled trial. JAMA 2009;301:2099-110.

15. Lenth, RV. 2006-2009. Java Applets for Power and Sample Size [Computer software]. <www.stat.uiowa.edu/ rlenth/Power > (Accessed December 11, 2009).

16. Urbaniak GC, Plous S. 2011. Research Randomizer (Version 3.0). $<$ www.randomizer.org/> (Accessed April 22, 2011)

17. Canadian Agency for Drug and Technologies in Health. 2011. Multidisciplinary treatment programs for patients with nonmalignant pain: A review of the clinical evidence, costeffectiveness, and guidelines. <www.cadth.ca/media/pdf/htis/ nov-2011/RC0304-000\%20Chronic\%20Pain\%20Programs.pdf> (Accessed July 18, 2012).

18. Fiellin DA, Reid MC, O'Connor PG. Screening for alcohol problems in primary care: A systematic review. Arch Intern Med 2000;160:1977-89.
19. Aertgeerts B, Buntinx F, Kester A. The value of the CAGE in screening for alcohol abuse and alcohol dependence in general clinical populations: A diagnostic meta-analysis. J Clin Epi 2004;57:30-9.

20. Brown RL, Rounds LA. Conjoint screening questionnaire for alcohol and drug abuse. Wis Med J 1995;94:135-40.

21. Matza LS, Yu-Isenberg KS, Coyne KS, et al. Further testing of the reliability and validity of the ASK-20 adherence barrier questionnaire in a medical center outpatient population. Curr Med Res Opin 2008;24:3197-206.

22. Norman GR, Streiner DL. Biostatistics, The Bare Essentials, 2nd edn. Shelton: People's Medical Publishing House 2008:186-92.

23. Leech NL, Barrett KC, Morgan GA. SPSS for Intermediate Statistics, 3rd edn. New York: Psychology Press, 2008:197-228.

24. Thabane L, Ma J, Chu R, et al. A tutorial on pilot studies: The what, why, and how. BMC Med Res Meth 2010;10:1.

25. Angst F, Brioschi R, Main CJ, Lehmann S, Aschilmann A. Interdisciplinary rehabilitation on fibromyalgia and chronic back pain: A prospective outcome study. J Pain 2006;7:807-15.

26. Glimbiewski JA, Hartwich-Tersek J, Rief W. Attrition in cognitivebehavioral treatment of chronic back pain. Clin J Pain 2010;26:593-601.

27. Hopwood CJ, Creech SK, Clark TS, Meagher MW, Morey LC. Predicting the completion of an integrative and intensive outpatient chronic pain treatment with the personality assessment inventory. J Pers Assess 2008;90:76-80.

28. Dysvik E, Vinsnes AG, Eikland OJ. The effectiveness of a multidisciplinary pain management programme managing chronic pain. Int J Nurs Pract 2004;10:224-34.

29. Sloots M, Dekker JH, Geertzen JH, Dekker J. Reasons for drop-out in rehabilitation treatment of native and non-native patients with chronic low back pain in the Netherlands: A medical file study. Eur J Phys Rehabil Med 2010;46:505-10.

30. Ware JE, Korsinski M, Bjorner JB, Turner-Bowker DM, Gandek B, Maruish ME. SF36v2 Health Survey: A Primer for Healthcare Providers. Lincoln: Qualimetric Incorporated 2008:2-3. 


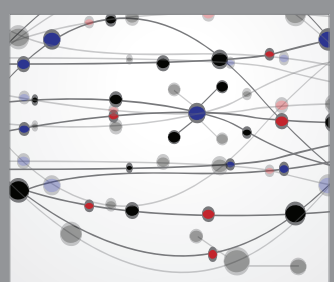

The Scientific World Journal
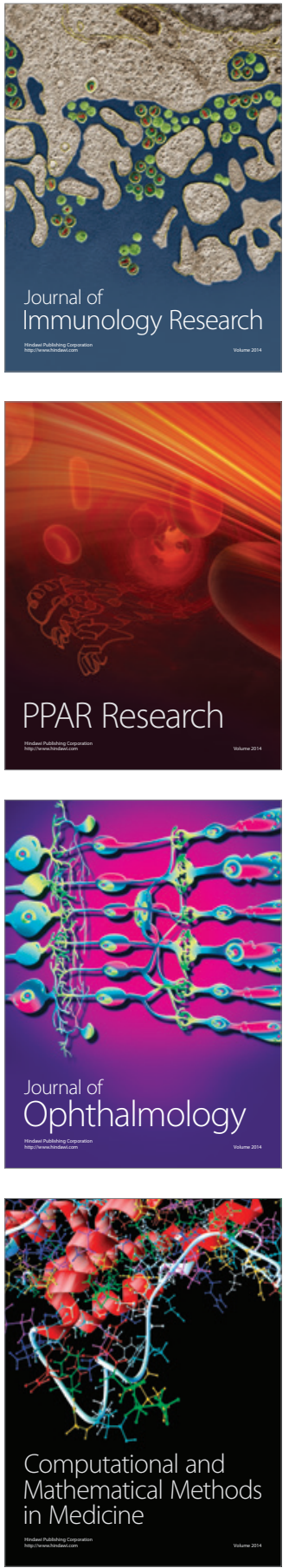

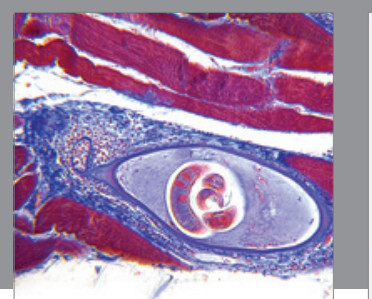

Gastroenterology Research and Practice

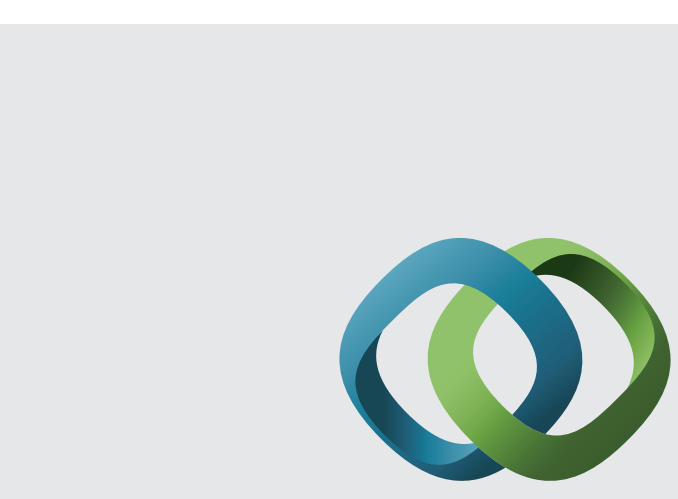

\section{Hindawi}

Submit your manuscripts at

http://www.hindawi.com
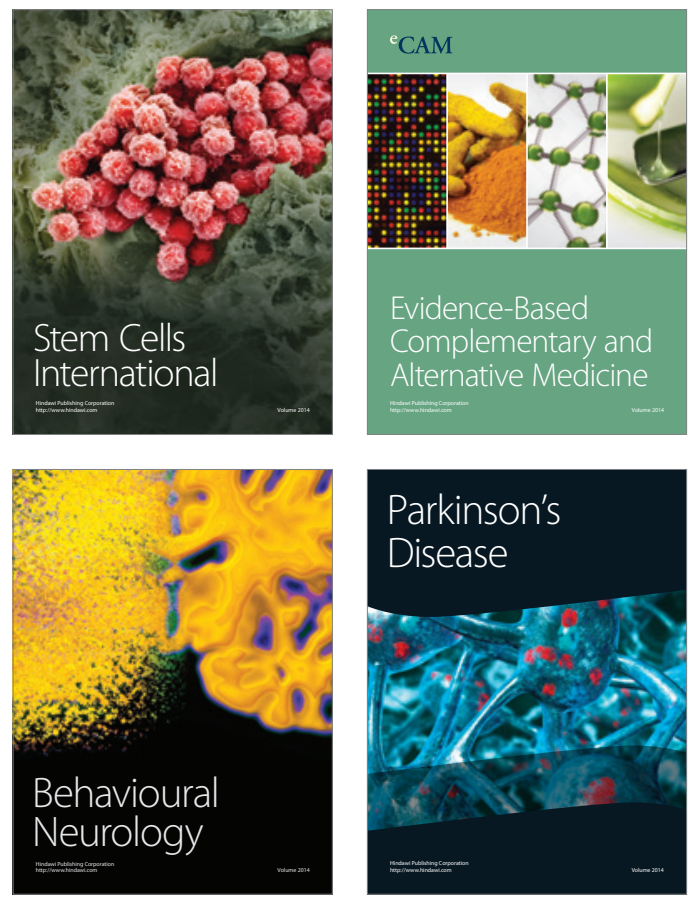
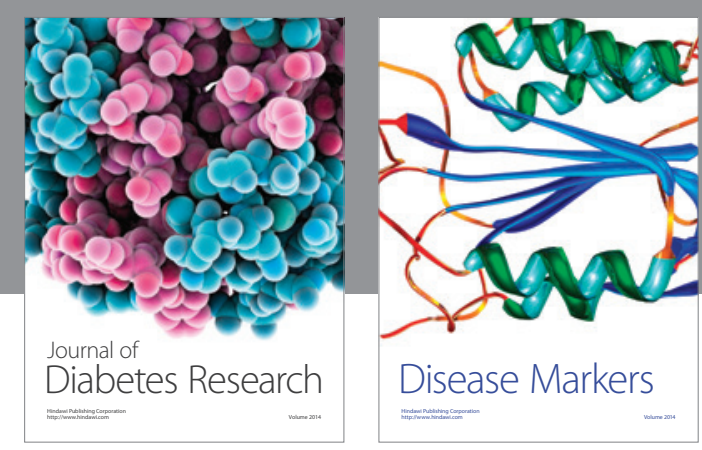

Disease Markers
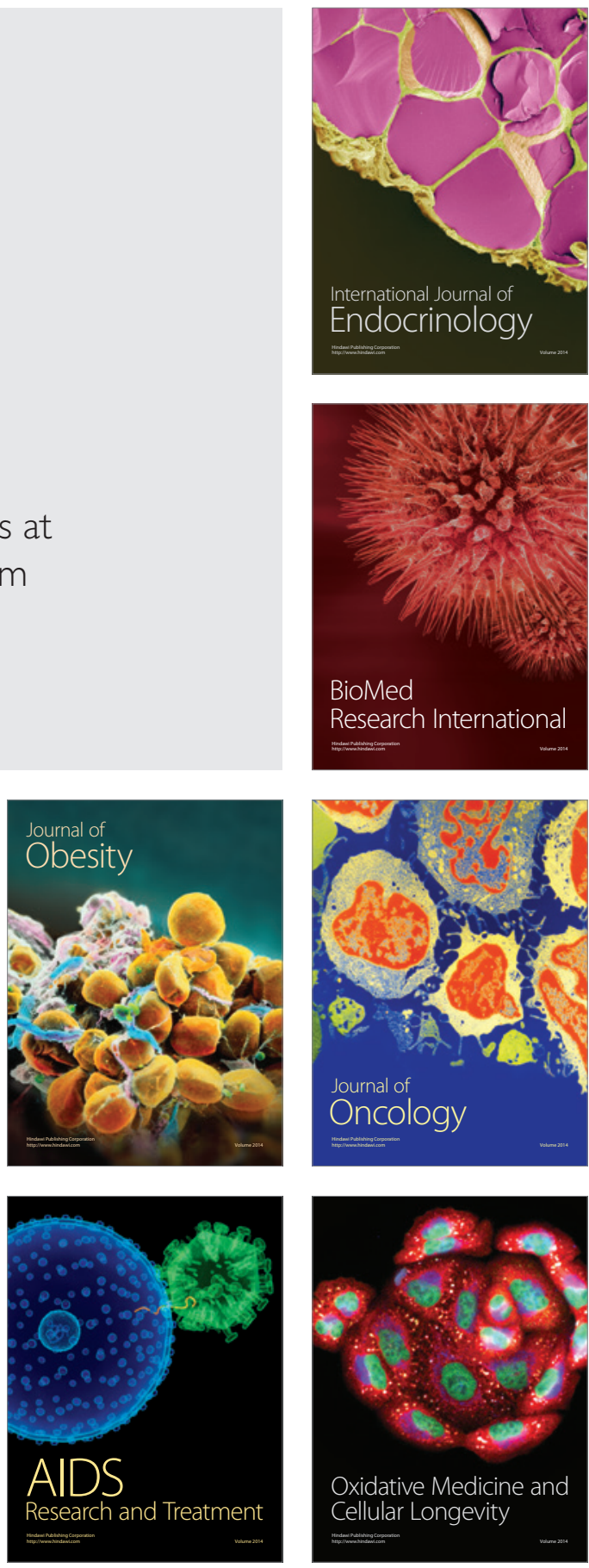